\title{
The Teaching Reform of Communication Principles Course based on Applied Technology University
}

\author{
Yuan Tang*, Jufang Li, Min Li and Xin Wang \\ City College of Science and Technology, Chongqing University, Chongqing 402167, China \\ *Corresponding author
}

\begin{abstract}
Keywords: Communication Principle; Teaching reform; Electrical \& Information Engineering; Technical Talent for Application.

Abstract. Basing on the starting point of training the person with the ability in applied technology and combining with our own experience on theory and practice teaching in the course of Communication Principle, it was discussed in detail that how to improve the teaching quality through the reforming and exploring from the aspects of teaching content, teaching methods, practical teaching and examination method in this paper. The practice of teaching proves that the teaching effect of the method is good and the learning initiative and ability in analyze and solve problems of students have been improved.
\end{abstract}

\section{Introduction}

Communication Principle is an important course for students of communication and electronic information specialties. It is also one of the major courses for the entrance examination for postgraduates of communication majors in many universities [1]. This course plays an important bridge among many courses in the curriculum system.

Based on the courses such as "Signal and System", "Probability Theory" and "High Frequency Electronic Circuits", Communication Principle mainly focuses on the basic concepts and principles of communication systems [2, 3]. It makes students master the basic analysis methods of communication systems, changes of waveform and spectrum during signal transmission and evaluation law of the performance for communication system. Moreover, it enables students to apply flexibly in the learning and work of follow-up courses, stimulates their interest and enthusiasm for communication, so that they have enough confidence and ability to adapt to this ever-changing field. The course involves a wide range of knowledge and theoretical, systematic, rich and abstract content, which need the ability of high mathematical analysis and close connection with pre-requisite courses for students. So, students are easy bored and most students may feel it very difficult to learn due to the limited time to studying in classroom and lack of perceptual knowledge in this regard.

\section{Problems in Traditional Teaching}

The traditional teaching methods are taking the teacher as the main body. Teaching processes are in full accordance with the teaching material chapter sequence. The study patterns for students are "listening, memory and examination". These phenomenon make students lack the sense of participation and seriously nullifies enthusiasm and interest in learning of student [4].

The experiment courses of Communication Principle focus on the box of Communication Principle provided by various manufacturers. The contents of the experiment are fixed and only satisfied with the verification of theoretical results. All of these problems make students a passive position and narrow scope of the hands-on operation. Moreover, the space for developing new experiments is severely restricted. The experimental effect is not ideal. The one-time investment capital for the laboratory is big. It is difficult to introduce new technology in the later stage. So, it is unfavorable to cultivate students' practical ability, innovation ability and comprehensive application of knowledge ability in traditional experiment course of Communication Principle.

In addition, the traditional examinations are paper type. Their examination questions mainly focus on the basic knowledge. For example, the communication system model, encoding and decoding mode, 
transmission rate and so on. The type of exam is highly prone to high scores and low performance. Although some students got high test scores, they do not use in practical terms.

\section{Measures of Teaching Reform}

\subsection{Content of courses}

In response to the above problems, combined with the training talents of the application-oriented technology universities and the actual situation of our students, we propose a novel teaching method. We broke the existing body of knowledge taught by chapter, and adopted the communication system model as the main line, and divided the teaching content into three modules: "source coding, channel coding and modulation and demodulation". In each module, we firmly grasp the two important indicators (validity and reliability) of evaluation of communication system performance.

With the ever-changing communications technology, the "Communication Theory" course is more basic to make more and more students feel that the knowledge from the classroom is too old and is seriously out of touch with the application of real life work. Therefore, it is urgent to introduce new popular communication technologies, such as CDMA, OFDM, MIMO, 5G, etc., to make students have an understanding of cutting-edge communication technologies and lay a foundation for subsequent practical applications.

\subsection{Teaching method}

The commonly used teaching methods include teaching methods, demonstration methods, practice methods, classroom discussion methods, heuristic contrast methods, case-based teaching, project-based teaching and so on. The key to achieving the expected teaching goals and effects is adopting flexible and diverse teaching methods for specific teaching content and formulating scientific and effective teaching methods. For example, when explaining the analog modulation, a variety of teaching methods such as case-based teaching, analog teaching, and Animated demo are comprehensive used to design the teaching process. The design process is shown in Table 1 in detail.

First of all, in order to stimulate the interest of students in exploration, some questions are proposed based on the well-known problem of communication between mobile phones. The process of transmitting electromagnetic signals by electromagnetic waves is introduced to stimulate students' interest in exploration and knowledge. After that, we use the analogy teaching method to compare the carrier to the vehicle. Such as using the actual example of 'boarding' to simulate the basic concept of modulation and carrier. That is, the carrier is similar to an airplane carrying a voice signal, and modulation is a process of placing a low-frequency voice signal on a high-frequency carrier. The very important function for modulation is that the spectrum can be linearly shifted. The comparison analyzing the modulation process of the signal from the time domain and the frequency domain is proved by taking amplitude modulation as an example. In the process of analyzing the principle of amplitude modulation, the formula should be diluted. We mainly fund on animation demo and waveform analysis to guide students to positive thinking and cultivate their ability to discover, analyze and solve problems. Finally, the wireless microphone to propagate the sound was taken as an example to strengthen the perception of the amplitude modulation process and introduce the problem of demodulation to prepare for the next lesson.

Table 1 The design of amplitude modulation teaching process

\begin{tabular}{|c|c|c|}
\hline Teaching session & Teaching content & Teaching methods \\
\hline Instance introduction & $\begin{array}{c}\text { Taking the communication between mobile phone } \\
\text { and mobile phone as an example, introducing } \\
\text { electromagnetic waves to transmit voice signals }\end{array}$ & Case-based teaching \\
\hline $\begin{array}{c}\text { Explain knowledge } \\
\text { points }\end{array}$ & $\begin{array}{c}\text { Analogizing the modulation with 'boarding" and } \\
\text { explaining the basic concepts of modulation and } \\
\text { carrier. }\end{array}$ & Analog teaching \\
\hline In-depth analysis & $\begin{array}{c}\text { Taking amplitude modulation as an example, } \\
\text { analyzing the modulation process of signals from the } \\
\text { time domain and the frequency domain }\end{array}$ & Animated demo \\
\hline
\end{tabular}




\begin{tabular}{|c|c|c|}
\hline \multicolumn{3}{|c|}{ Cont. to Table 1 } \\
\hline Example verification & $\begin{array}{c}\text { Using wireless microphones to spread sound as an } \\
\text { example to enhance cognitive effects }\end{array}$ & Physical demonstration \\
\hline Summary expansion & $\begin{array}{c}\text { Summarizing the process of signal modulation, } \\
\text { leading to the problem of signal demodulation }\end{array}$ & Teaching method \\
\hline
\end{tabular}

\subsection{Practical teaching}

Practical teaching is mainly based on the hardware verification experiments using experimental boxes and combined with Lab-VIEW simulation software to assist teaching [5, 6]. The hardware experimental boxes integrated the various modules involved in the communication system. Students can observe the experimental results by connecting the ports with the reference wires through the reference experiment guide. For example, when doing the experiment of CMI coding and decoding, students could enhance their understanding of the CMI coding principle through an oscilloscope comparing the waveform of the coded input and encoded output data.

Lab-VIEW is virtual instrument platform software developed by National Instruments (NI). It uses a graphical programming language $G$ to write programs. The generated program is in the form of a block diagram. Programming is just like designing a circuit diagram. It is easy to learn and use. It can be mastered and applied to practice in a short period of time. Students are very interested in the introduction of this new technology. They have a high degree of enthusiasm. After mastering the basic design methods, they can quickly design their own technical links and instruments. The use of Lab-VIEW virtual instrument for software simulation makes the experimental content flexible and design. This allows the experiment to complement both the basic theory and the hardware experiment. It is not only enhanced the diversity of experiments and expanded the scope of the experiment.

\subsection{Examination mode}

The course assessments are no longer measured by a single final exam paper. We combined the various aspects of assessment methods such as course theory assessment, practical application ability assessment, new technology research report assessment and process assessment. These are conducive to the dynamic and comprehensive evaluation of the overall quality of students. The structure of the assessment method is shown in Fig. 1.

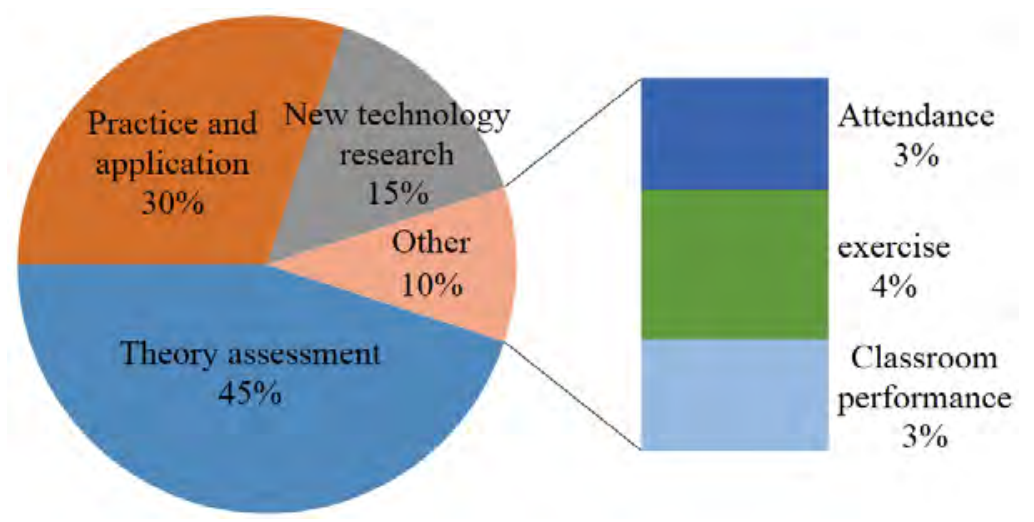

Fig.1 The structure chart of assessment

The practical application ability assessment includes experimental classroom operation and Lab-VIEW simulation. For the experimental classroom, the mode of on-site operation and reply is adopted to mainly inspect the student learning situation of basic concepts and working principles of the communication system, the analysis of the circuit design ideas and the ability to write reports.

The evaluation of new technology learning effects is intended to promote students to independently research and learn new technologies and new theories in the field of communications. Students are required to complete the research report of 2000 3000 words after learning the corresponding basic theory.

In addition, it is necessary to comprehensively assess the daily performance of students, including attendance, classroom performance and homework, accounting for 3\%, 3\% and 4\% respectively. 


\section{Summary}

In view of the communication system model theory, this paper applied student-centered of combining verification and simulation experiments teaching model and used modern information technology to system propose a reform case of Communication Principles course based on the applied technology university, which reformed the traditional teaching concept, teaching content, teaching methods and assessment methods. Judging from the preliminary effect of the current curriculum reform, students not only have interest and enthusiasm for the study of the communication principle course, but also improve their ability to analyze and solve problems. So, this shows that through the above teaching practice, the initial success of the teaching reform has been achieved, and built a foundation for continuing to promote the innovation and entrepreneurship education of the curriculum. But, the construction process of the Communication Principles course is a long-term. It should be carried out throughout the course of the course. Only by persisting in perseverance, can we continuously achieve new results and better serve innovation and entrepreneurship education.

\section{Acknowledgment}

This paper is the research result of the 2018 Chongqing University of City College Science and Technology Transformation Pilot Project (City College Science and Technology, Chongqing University [2018] No. 93) and the 2018 Chongqing University of City College Science and Technology School-level Teaching Reform Project (YJ1826).

\section{References}

[1]. S. Y. Zhang. "Exploration of the Teaching Reform in the Course in Communication Principles." Journal of Electrical \& Electronic Engineering Education, Vol. 25, pp. 12-13, Oct. 2003. (In Chinese)

[2]. L. N. Cao, Y. L. Zhang, and Y. C. Wang. “Teaching Case of communication principles-Teaching strategy of digital modulation,” The 3rd International Annual Conference on Teaching Management and Curriculum Construction, 2012:4. (In Chinese)

[3]. F. Chen. "Teaching Reform in the Course of Communication Principles." Advanced Technology in Teaching - Proceedings of the 2009 3rd International Conference on Teaching and Computational Science (WTCS 2009). Springer Berlin Heidelberg, 2012:311-316.

[4]. F. Shu W. J. Qiu, and J. T. Sun. "Teaching Reform on the Course of Communication Principles." Journal of Electrical \& Electronic Education, Vol. 28, pp. 23-25, Feb 2006. (In Chinese)

[5]. A. J. Sun, and Y. Liu. "Study on Experimental Teaching of Communication Principle Based on Software Simulation." Research \& Exploration in Laboratory, Vol. 29, pp. 135-137, Jan 2010. (In Chinese)

[6]. D. M. Ma, and Z. W. Zhu. "Reform and exploration on the experimental teaching of communication principle." Laboratory Science, 2010. (In Chinese) 